\title{
PEMANFAATAN E-COMMERCE DALAM PEBELAJARAN MANAJEMEN USAHA KECIL DAN MENENGAH
}

\author{
Endra Yuafanedi Arifianto, Mochammad Choiri \\ Jurusan Teknik Industri, Universitas Brawijaya \\ Email: endra@ub.ac.id
}

\begin{abstract}
Abstrak
Penerapan teknologi informasi khususnya e-commerce dalam pembelajaran dikelas manajemen usaha kecil dan menengah berhasil meningkatkan pemahaman mahasiswa. Pemberian materi yang sebelumnya hanya berdasarkan konsep dan teori dirubah dengan terobosan tugas praktik lapangan dengan bekerja sama dengan pelaku usaha komunitas UKM Kota Malang. Berdasarkan hasil pembahasan penelitian ini memiliki kesimpulan penerapan teknologi informasi khususnya $e$-commerce dalam pembelajaran di kelas manajemen usaha kecil dan menengah memberikan dampak nyata kepada kemampuan dan tingkat pemahaman mahasiswa tentang materi perkuliahan, mahasiswa mendapatkan pengalaman dan wawasan langsung secara nyata tentang bisnis, mahasiswa mampu merancang dan menguji e-commerce prototype, mahasiswa terlibat secara langsung dalam membantu menyelesaikan permasalahan pelaku usaha khususnya bidang promosi dan komunikasi pelanggan, kelas manajemen usaha kecil dan menengah mampu menghasilkan media promosi yang bisa dimanfaatkan secara langsung oleh pelaku usaha.
\end{abstract}

Kata kunci: E-commerce, Manajemen Usaha Kecil dan Menengah

\section{UTILIZATION OF E-COMMERCE IN LEARNING SMALL AND MEDIUM ENTERPRISE MANAGEMENT}

\author{
Endra Yuafanedi Arifianto, Mochammad Choiri \\ Department of Industrial Engineering, Universitas Brawijaya \\ Email:endral@ub.ac.id
}

\begin{abstract}
Application of information technology, especially e-commerce in the classroom management of small and medium enterprises managed to improve student understanding. The provision of material that was previously only based on the concept and theory was changed with the breakthrough of field practice tasks in collaboration with the business community of SMEs of Malang City. Based on the results of this study, it is concluded that the application of information technology especially e-commerce in learning in the small and medium enterprise management class gives a real impact to the ability and level of students understanding about the lecture material, the students get real experience and direct insight into the business, the students are able to design and test e-commerce prototype, students are directly involved in helping solve business problems especially in the field of customer promotion and communication, small and medium business management class capable of producing promotional media that can be used directly by business actors.
\end{abstract}

Keywords: E-commerce, Small and Medium Enterprise Management 


\section{PENDAHULUAN}

Persaingan penyelenggara pendidikan saat ini memiliki tantangan nyata di bidang pemanfaatan teknologi informasi. Berbagai perguruan tinggi harus mampu beradaptasi, berkreasi dan berinovasi dalam memanfaatkan teknologi informasi di dalam proses belajar mengajar. Setiap aktivitas perguruan tinggi saat ini memiliki dampak di pemeringkatan melalui pemanfaatan teknologi informasi. Salah satu contoh nyata pemanfaatan teknologi Webometrics selalu merilis peringkat perguruan tinggi menggunakan presence (20\%), impact $(50 \%)$, openness (15\%), dan excellence $(15 \%)$. Penjelasan tentang presence $(20 \%)$ merupakan jumlah halaman web host pada webdomain utama dari universitas yang diindeks oleh mesin pencari Google. Impact (50\%) merupakan kualitas konten dengan menghitung semua external inlinks yang diterima oleh webdomain universitas dari pihak ketiga. Openness (15\%) merupakan jumlah file dokumen seperti Adobe Acrobat (.pdf), Adobe PostScript (.ps, .eps), Microsoft Word (.doc,.docx) dan Microsoft Powerpoint (.ppt, .pptx) yang terindeks mesin pencari (Google Scholar). Excellence (15\%) merupakan jumlah publikasi artikel ilmiah perguruan tinggi yang bersangkutan yang terindeks di Google Scholar atau mesin pencari yang menjadi indikator penilaian webometrics.

Oleh karena itu saat ini perguruan tinggi saling berlomba lomba untuk mengoptimalkan teknologi informasi dalam aktivitas pendidikan. Berbagai kebijakan diterapkan diantaranya : menyarankan menggunakan email dengan domain universitas untuk seluruh dosen dan pegawai, memberikan akses layanan internet yang mudah dan cepat, menyarankan dosen dan pegawai memiliki web blog, sistem perkuliahan yang sudah online dan sebagainya. Bidang pendidikan juga ikut terlibat secara masif dalam persaingan di dunia maya dengan memanfaatkan teknologi informasi. Beberapa perguruan tinggi ternama bahkan harus mengalokasikan anggaran ratusan juta per tahunnya untuk mendukung aktivitas ini. Kemampuan perguruan tinggi mengoptimalkan teknologi informasi diyakini berbanding lurus dengan kemungkinan memenangkan pasar. Hampir dipastikan calon mahasiswa atau orang tua mahasiswa (masyarakat umum) akan memanfaatkan teknologi informasi untuk mencari informasi tentang perguruan tinggi yang akan di pilihnya. Kemudahan akses internet ini menjadikan masyarakat cepat mendapatkan informasi yang valid, sehingga masyarakat lebih mudah membandingkan antar perguruan tinggi.

Penerapan teknologi informasi khususnya pemanfaatan ecommerce sudah sangat teruji manfaatnya untuk mempromosikan produk barang atau jasa. Tren bisnis saat ini sudah memasuki era Industri 4.0 yang tidak bisa terpisahkan dengan online/internet. E-commerce menjual 
produk kepada konsumen secara online. Proses menjual dan membeli dengan memanfaatkan intenet dapat disebut dengan e-commerce (Chandra dkk., 2004). Penerapan ecommerce dalam bisnis jasa, retail dan manufaktur sudah menjamur saat ini. E-commerce adalah membuat, mengelola, dan meluaskan hubungan komersial secara online (Kottler, 2002). Prinsip ini bisa diadopsi di sistem pendidikan sehingga mampu menembus/menginformasikan ke seluruh wilayah tanpa ada sekat geografis. Perlunya mendukung visi dan misi perguruan tinggi sekaligus berkompetisi dalam pemanfaatan teknologi informasi khususnya pemanfaatan e-commerce dalam proses pembelajaran, maka kami bermaksud melakukan penelitian tingkat keberhasilan proses pembelajaran di kelas usaha kecil dan menengah dengan pemanfaatan e-commerce dalam penyampaian materi.

\section{METODE PENELITIAN}

Penelitian ini dirancang dari segi teknik pengumpulan data, penelitian ini termasuk jenis penelitian survey, yakni penelitian yang mengambil sampel dari suatu populasi dengan menggunakan kuesioner sebagai alat pengumpulan data. Berdasarkan analisis datanya, penelitian ini termasuk penelitian analitis, yaitu penelitian yang menganalisis data sampel dengan statistik deskriptif dan statistik induktif (inferensi) yang digeneralisasi untuk kesimpulan populasi (Arikunto, 2002).

Objek dalam penelitian ini adalah 23 mahasiswa dalam kelas manajemen usaha kecil dan menengah serta 23 owner pelaku usaha dari komunitas UKM Kota Malang. Penelitian ini memiliki beberapa identifikasi masalah, yaitu : tantangan dunia pendidikan mengharuskan memanfaatkan teknologi informasi dalam aktivitas belajar mengajar, materi dalam kelas usaha kecil dan menengah harus tersampaikan dengan cara yang tepat, materi kuliah tidak hanya disampaikan hanya secara teori, mahasiswa memerlukan wawasan dan pengalaman baru terlibat dalam memecahkan masalah pelaku usaha kecil dan menengah, masalah pelaku usaha di komunitas UKM Kota Malang dalam menjalankan bisnisnya.

Berdasarkan identifikasi masalah tersebut, penelitian ini merumuskan masalah bagaimana peran teknologi informasi khususnya e-commerce dalam pembelajaran kelas usaha kecil dan menengah. Sejauh mana hasil dan dampak pemanfaatannya dalam mentransfer keilmuan di kelas UKM berdasarkan studi lapangan dengan melibatkan secara langsung pelaku usaha di komunitas UKM Kota Malang. Sedangkan studi Pustaka diperlukan untuk menguatkan konsep dan materi pembelajaran secara teori sebelum mahasiswa diajak secara langsung terjun ke lapangan/praktik. Tahapan penelitian selanjutnya dilakukan pengambilan data melalui kuisioner untuk 
mahasiswa dan pelaku usaha, wawancara untuk pelaku usaha dan survey kelokasi usaha oleh mahasiswa. Setelah mendapatkan data maka dilakukan pengolahan data menggunakan bantuan micro soft excel dan pengembangan sistem yang menggunakan tahapan System Development Life Cycle (SDLC) yang terdiri dari perencanaan, analisa sistem, perancangan, implementasi dan pengujian prototype sistem.

Perancangan e-commerce. Tahap ini merupakan salah satu terobosan di pembelajaran kelas usaha kecil dan menengah. Mahasiswa secara langsung praktik memanfaatkan teknologi informasi untuk menyelesaikan permasalahan mitra/owner pelaku usaha dari komunitas UKM Kota Malang. Dalam perancangan ecommerce menggunakan tools WordPress dan desain sistem (design interface dan design algoritma). Proses pengujian dilakukan tiga kali, yaitu pengujian verifikasi, pengujian validasi dan pengujian prototype. Proses pengujian memberikan rekomendasi hasil perancangan sistem berjalan dengan baik atau tidak. Tahap evaluasi adalah tahap terkahir dalam penelitian ini. Evaluasi dilakukan untuk mengetahui tingkat keberhasilan kegiatan pembelajaran kelas usaha kecil dan menengah. Sedangkan diagram alir penelitian dapat dilihat dibawah ini.

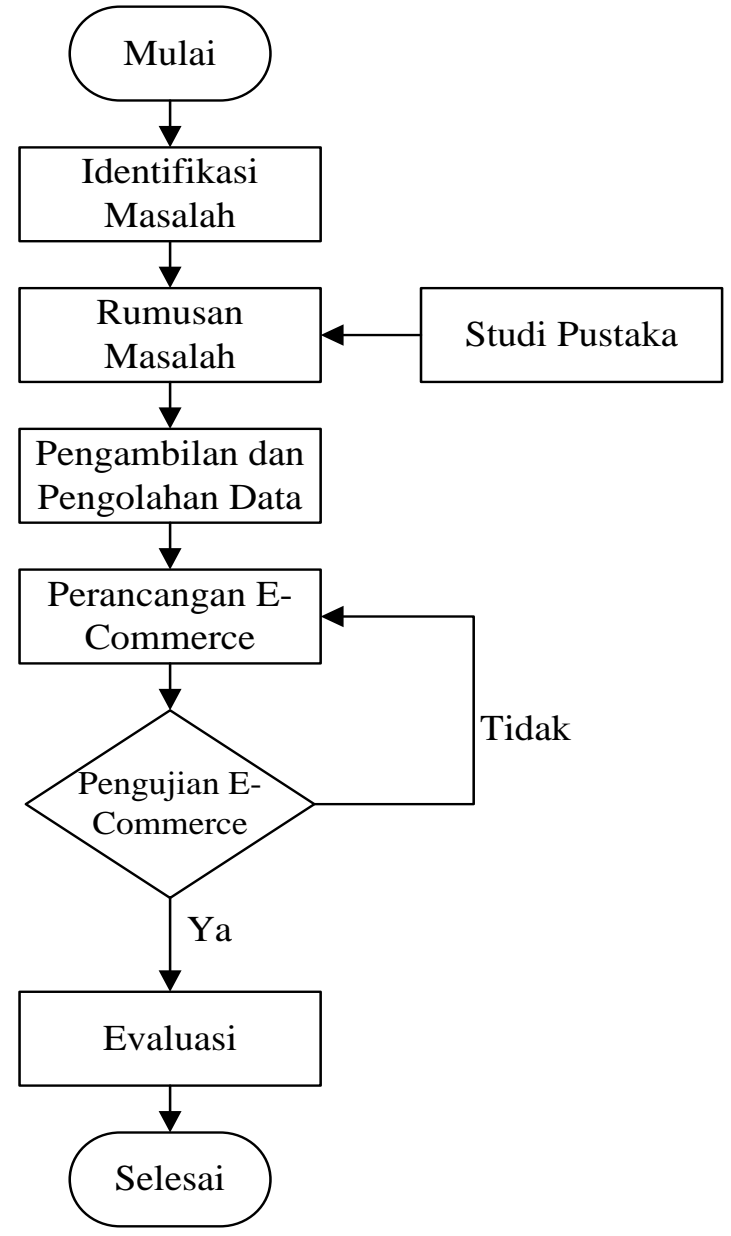

\section{Gambar 1. Diagram Alir Penelitian Pemanfaatan E-commerce}

\section{HASIL DAN PEMBAHASAN}

Kelas manajemen usaha kecil dan menengah memiliki beberapa materi/bahan ajar yang harus disampaikan dalam kegiatan belajar mengajar sesuai dengan Rencana Pembelajaran Semester (RPS), yang dijelaskan dalam tabel dibawah ini. 
Tabel 1. Bahan Ajar Kelas Manajemen Usaha Kecil dan Menengah

\begin{tabular}{|c|c|c|}
\hline No & Bahan Ajar & Keterangan \\
\hline 1 & $\begin{array}{l}\text { Pengantar Manajemen Usaha } \\
\text { Kecil dan Menengah }\end{array}$ & $\begin{array}{l}\text { Pengertian dan empat dasar fungsi manajemen dalam usaha } \\
\text { kecil dan Menengah }\end{array}$ \\
\hline 2 & $\begin{array}{l}\text { Pengertian Usaha } \\
\text { Usaha Kecil dan } \\
\text { Usaho, } \\
\text { Menengah }\end{array}$ & $\begin{array}{l}\text { Pengertian Usaha Kecil dan Menengah, Perbedaan Usaha } \\
\text { Mikro, Usaha Kecil dan Usaha Menengah, Peraturan } \\
\text { pemerintah tentang Usaha Kecil dan Menengah, Pengertian } \\
\text { Industri Kecil dan Menengah (IKM) }\end{array}$ \\
\hline 3 & $\begin{array}{l}\text { Membedah Konsep Dasar } \\
\text { Usaha Kecil dan Menengah }\end{array}$ & $\begin{array}{l}\text { Membangun Jenis Usaha berdasarkan Kebutuhan Masyarakat, } \\
\text { Pola Distribusi dari Hulu sampai Hilir, Merancang struktur } \\
\text { organisasi UKM, Penerapan Diagram Input Proses dan Output } \\
\text { (IPO) dalam UKM }\end{array}$ \\
\hline 4 & $\begin{array}{l}\text { Peran UKM dalam } \\
\text { Perekonomian Daerah }\end{array}$ & $\begin{array}{l}\text { Menciptakan lapangan kerja, Merekrut tenaga kerja local, } \\
\text { Meningkatkan penghasilan masyarakat sekitar }\end{array}$ \\
\hline 5 & $\begin{array}{l}\text { Pengenalan Manajemen } \\
\text { Pemasaran dalam UKM }\end{array}$ & $\begin{array}{l}\text { Pengertian dan pembagian Segmentasi Pasar dalam UKM, } \\
\text { Pengertian dan penerapan Targeting UKM, Pengertian } \\
\text { Positioning produk UKM, Membuat Branding UKM, Brand } \\
\text { Activation }\end{array}$ \\
\hline 6 & $\begin{array}{l}\text { Klusterisasi } \\
\text { Pengembangan UKM }\end{array}$ & $\begin{array}{l}\text { Membagi dan menganalisa potensi lokal daerah terkait } \\
\text { keberadaan UKM, Metode klusterisasi UKM, Metode } \\
\text { pengembangan UKM }\end{array}$ \\
\hline 7 & $\begin{array}{l}\text { Penerapan Manajemen } \\
\text { Teknologi dalam UKM }\end{array}$ & $\begin{array}{l}\text { Pengertian dan penerapan Teknologi Informasi dalam UKM, } \\
\text { Penerapan teknologi tepat guna dalam proses produksi UKM, } \\
\text { Penerapan teknologi ramah lingkungan dalam menjalankan } \\
\text { UKM }\end{array}$ \\
\hline 8 & $\begin{array}{l}\text { Inovasi dan Kreativitas dalam } \\
\text { UKM }\end{array}$ & $\begin{array}{l}\text { Memunculkan Inovasi produk dan jasa UKM, Menumbuhkan } \\
\text { kreativitas dalam setiap operasional UKM, Penerapan Blue } \\
\text { Ocean Strategy dalam UKM }\end{array}$ \\
\hline 9 & $\begin{array}{l}\text { Manajemen Keuangan dan } \\
\text { Pemodalan dalam UKM }\end{array}$ & $\begin{array}{l}\text { Mengenal Pembukuan keuangan UKM, Arus Kas/Cash Flow, } \\
\text { Pengelolaan Aset, HPP, BEP, Laporan Keuangan, Laporan laba } \\
\text { rugi UKM, Pemodalan UKM dari pemerintah dan sumber } \\
\text { lainnya }\end{array}$ \\
\hline 10 & Manajemen Mutu UKM & $\begin{array}{l}\text { Standarisasi produk/jasa UKM level nasional, Standarisasi } \\
\text { produk/jasa UKM level internasional, Startegi mengelola Mutu } \\
\text { suatu produk/jasa UKM }\end{array}$ \\
\hline 11 & $\begin{array}{l}\text { Sinergitas Pengembangan } \\
\text { UKM ke level Internasional }\end{array}$ & $\begin{array}{l}\text { Peran Akademisi/Kampus sebagai pendamping UKM dan } \\
\text { sumber keilmuan, Peran Pemerintah sebagai pembina UKM dan } \\
\text { regulator, Peran Pemodal sebagai penyokong dana UKM, Peran } \\
\text { Antar UKM bekerjasama di bidang yang sama }\end{array}$ \\
\hline 12 & $\begin{array}{lc}\text { Strategi } & \text { UKM } \\
\text { Internasional (Eksport) }\end{array}$ & $\begin{array}{l}\text { Strategi menembus pasar MEA dan Internasional, Strategi } \\
\text { Internal UKM : standarisasi mutu produk/jasa, kemampuan } \\
\text { SDM, Kapasistas Produksi, Penerapan Teknologi, Internet } \\
\text { Marketing, perizinan, distribusi. Strategi Eksternal UKM : } \\
\text { Kondisi sosial ekonomi, politik negara, sumberdaya alam, } \\
\text { penetrasi pasar eksport }\end{array}$ \\
\hline
\end{tabular}

Berdasarkan tabel 1 diatas, maka e-commerce. Indikator pertama keberhasilan diperlu terobosan dalam kegiatan penelitian, berdasarkan data kuisioner dan pembelajaran di kelas tidak hanya diskusi tingkat pemahaman mahasiswa menyampaikan bahan ajar secara teori saja namun perlu ada praktik langsung sebelum dengan sesudah pemanfaatan dilapangan. Salah satunya dengan teknologi informasi khususnya e-commerce dalam membantu menyelesaikan masalah pemanfaatan teknologi informasi khususnya pelaku usaha. 


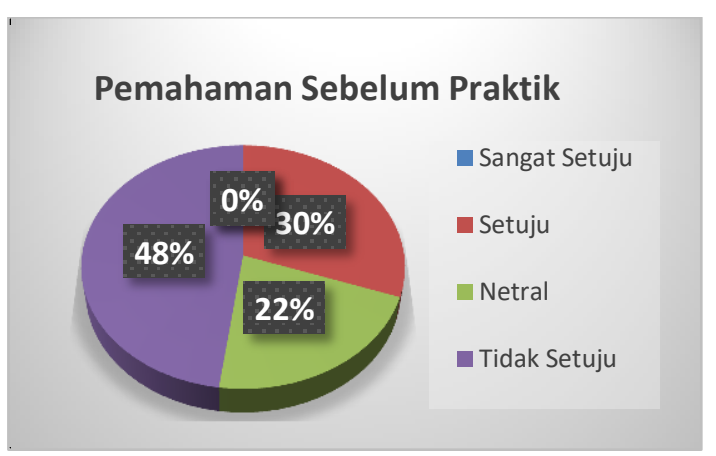

Gambar 2. Grafik Pemahaman Tingkat

Mahasiswa Sebelum Praktik

Penjelasan gambar 2 diatas, mahasiswa yang telah memahami permasalahan pelaku usaha dan materi penerapan teknologi informasi e-commerce di UKM sebanyak $30 \%$ setuju artinya sudah paham, sebanyak $23 \%$ netral artinya masih setengah paham, sebanyak $48 \%$ tidak setuju artinya belum paham. Setelah diberikan materi secara teori, tugas praktik lapangan, merancang $e$ commerce maka ada perubahan tingkat pemahaman mahasiswa seperti gambar 3 .

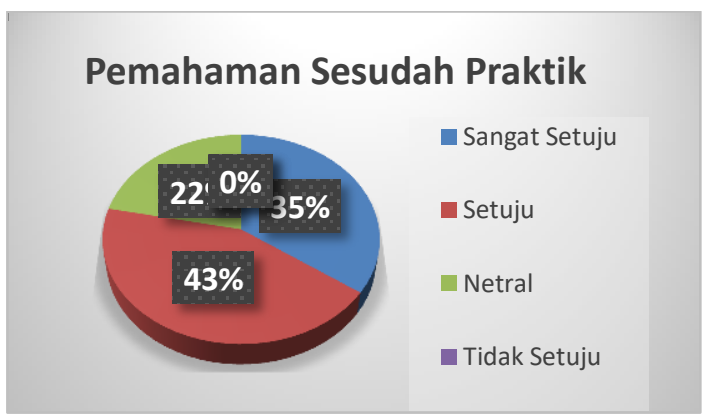

Gambar 3. Grafik Pemahaman Tingkat

Mahasiswa Sesudah Praktik
Berdasarkan perbandingan gambar 2 dan gambar 3 grafik tingkat pemahaman mahasiswa sebelum praktik menggunakan $e$ commerce dalam memahami materi kuliah sekaligus memberikan solusi terhadap permasalahan pelaku usaha dengan tingkat pemahaman sesudah praktik ada perubahan. Gambar 3 memberikan penjelasan sebanyak $35 \%$ sangat setuju artinya mahasiswa sangat paham tentang permasalahan pelaku usaha dan materi penerapan teknologi informasi di UKM, sebanyak $43 \%$ setuju artinya mahasiswa sudah paham dan $22 \%$ netral artinya mahasiswa setengah paham.

Indikator kedua keberhasilan penelitian, berdasarkan hasil kuisioner dan proses perancangan e-commerce dari pelaku usaha kecil dan menengah dari komunitas UKM Kota Malang. Sebanyak 23 pelaku usaha yang menjadi tempat praktik lapangan mahasiswa dalam menjalankan tugas kelas manajemen usaha kecil dan menengah memberikan jawaban terkait kuisioner yang hasil rekapitulasinya dapat dijelaskan di tabel 2 dibawah ini. 
Tabel 2. Rekapitulasi Kuisioner Pelaku Usaha

\begin{tabular}{|c|c|c|c|c|c|c|}
\hline No & Bidang Usaha & SS & $\mathbf{S}$ & $\mathbf{N}$ & TS & STS \\
\hline 1 & Konveksi Seragam & $\sqrt{ }$ & & & & \\
\hline 2 & Konveksi Jilbab & $\sqrt{ }$ & & & & \\
\hline 3 & Konveksi Gamis & & $\sqrt{ }$ & & & \\
\hline 4 & Kerajinan Tangan/ Craft Taliku & $\sqrt{ }$ & & & & \\
\hline 5 & Kerajinan Kayu & $\sqrt{ }$ & & & & \\
\hline 6 & Kuliner Roti Kasur & & $\sqrt{ }$ & & & \\
\hline 7 & Kuliner Segobong & $\sqrt{ }$ & & & & \\
\hline 8 & Kuliner Takoyaki & $\sqrt{ }$ & & & & \\
\hline 9 & Kuliner Kripik Tempe Mayla Jaya & $\sqrt{ }$ & & & & \\
\hline 10 & Kuliner Kripik Tempe Sedulur & $\sqrt{ }$ & & & & \\
\hline 11 & Kuliner Kripik Buah & & & $\sqrt{ }$ & & \\
\hline 12 & Kuliner Oleh oleh Khas Malang & & $\sqrt{ }$ & & & \\
\hline 13 & Camilan Khas Malang & & $\sqrt{ }$ & & & \\
\hline 14 & Kerajinan Tangan Klobot Jagung & & & $\sqrt{ }$ & & \\
\hline 15 & Kerajinan Tangan/ Craft Arema & & & $\sqrt{ }$ & & \\
\hline 16 & Kuliner Bumbu Dapur Cap Bawang & & $\sqrt{ }$ & & & \\
\hline 17 & Kuliner Bakso Malang & & & $\sqrt{ }$ & & \\
\hline 18 & Kuliner Bakso Arema & $\sqrt{ }$ & & & & \\
\hline 19 & Minuman Susu Kedelai dan Sinom & & & $\sqrt{ }$ & & \\
\hline 20 & Minuman Sari Apel Khas Malang & $\sqrt{ }$ & & & & \\
\hline 21 & Pempek Wicak & & $\sqrt{ }$ & & & \\
\hline 22 & Kuliner Aneka Kripik & $\sqrt{ }$ & & & & \\
\hline 23 & Abon Kelinci & & $\sqrt{ }$ & & & \\
\hline
\end{tabular}

Berdasarkan tabel diatas diketahui informasi dapat segera di atasi. Keberadaan sebanyak 11 pelaku usaha menyatakan sangat setuju artinya penerapan e-commerce sangat membantu mengatasi permasalahan mereka khususnya dibidang promosi dan komunikasi dengan pelanggan, sebanyak 7 pelaku usaha yang setuju artinya penerapan e-commerce dapat membantu dan sebanyak 5 pelaku usaha menjawab netral artinya penerapan e-commerce setengah membantu mereka. Para pelaku usaha sangat berharap program seperti ini bisa selalu dilakukan sepanjang tahun, sehingga bila terjadi permasalahan di lapangan terkait usaha khususnya promosi dan komunikasi mahasiswa dalam kegiatan ini sangat membantu untuk memecahkan masalah yang ada.

Indikator ketiga keberhasilan penelitian, berdasarkan output nyata dari perancangan dan pengujian e-commerce. Berikut contoh perancangan e-commerce mahasiswa yang dimanfaatkan untuk mempermudah promosi produk pelaku usaha komunitas UKM Kota Malang. Ketika proses perancangan ini, mahasiswa bisa belajar sambil praktik langsung sehingga pemahaman tentang materi perkuliahan tantang penerapan teknologi bisa lebih dipahami. 


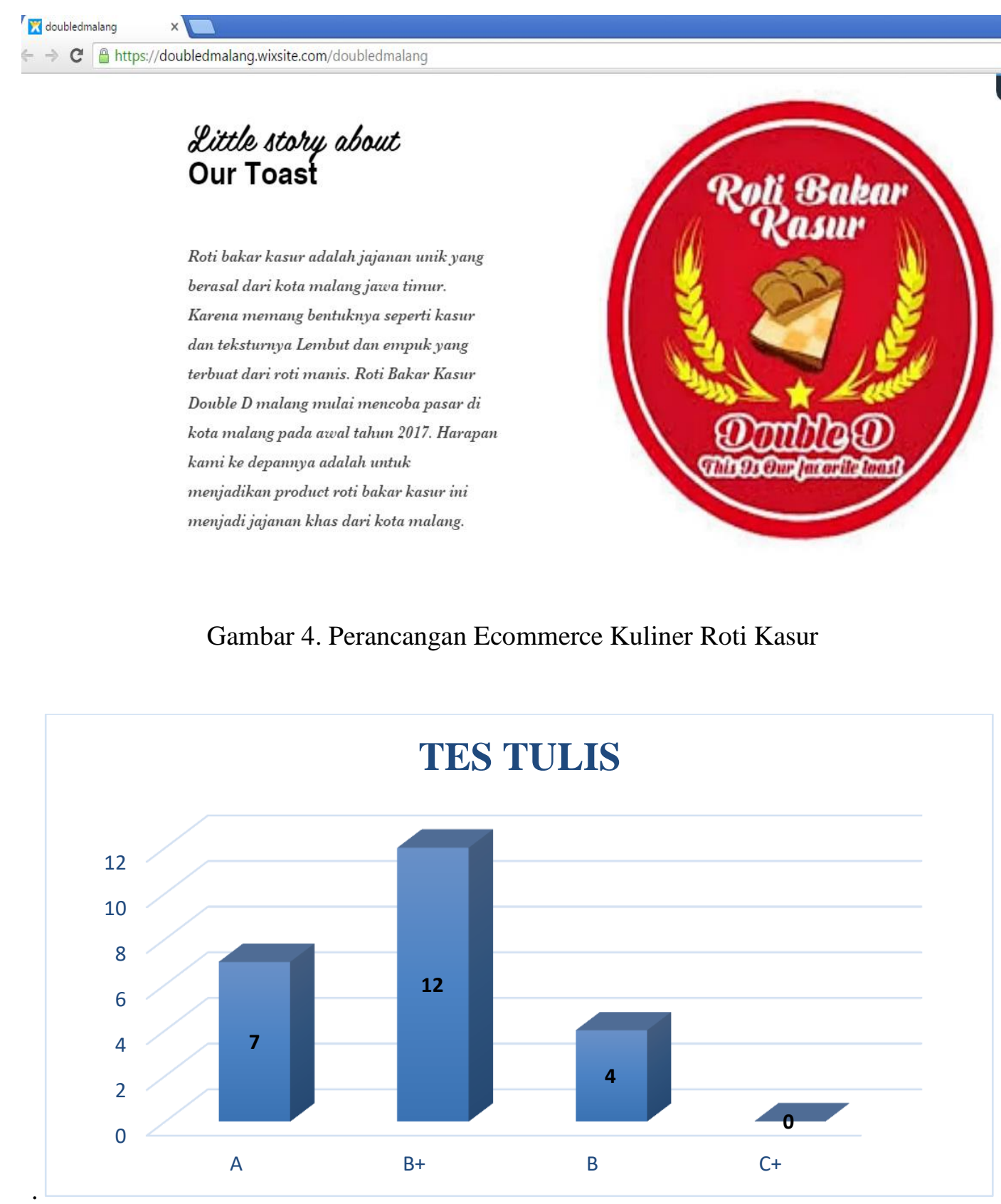

Gambar 5. Hasil Tes Tulis Mahasiswa

Berdasarkan hasil tes tulis mahasiswa yang memperoleh nilai A sebanyak 7 mahasiswa, nilai $\mathrm{B}+$ sebanyaj 12 mahasiswa, nilai B sebanyak 4 mahasiswa. Hasil evaluasi tes tulis ini sangat bagus.

\section{KESIMPULAN DAN SARAN}

Penerapan teknologi informasi khususnya ecommerce dalam pembelajaran di kelas manajemen usaha kecil dan menengah memberikan dampak nyata kepada 
kemampuan dan tingkat pemahaman mahasiswa tentang materi perkuliahan, mahasiswa mendapatkan pengalaman dan wawasan langsung secara nyata tentang bisnis, mahasiswa mampu merancang dan menguji eommerce prototype, mahasiswa terlibat secara langsung dalam membantu menyelesaikan permasalahan pelaku usaha khususnya bidang promosi dan komunikasi pelanggan, kelas manajemen usaha kecil dan menengah mampu menghasilkan media promosi yang bisa dimanfaatkan secara langsung oleh pelaku usaha.

Ada empat indikator keberhasilan penelitian ini, hasil tingkat pemahaman mahasiswa sebelum dan sesudah praktik, hasil kuisioner pelaku usaha komunitas UKM Kota Malang, hasil perencangan dan pengujian e-commerce, dan hasil tes tulis mahasiswa. Meskipun pemanfaatan $e$ commerce telah berhasil membantu proses pembelajaran kelas manajemen usaha kecil dan menengah, masih perlu ada perbaikan secara bertahap untuk metode pembelajaran yang lebih baik lagi.

\section{DAFTAR PUSTAKA}

Arikunto, Suharsimi. (2002). Prosedur Penelitian Suatu Pendekatan Pratek. Jakarta: PT. Renika Cipta

Arsyad, Azhar. (2002). Media Pembelajaran. Jakarta: PT. Rajagrafindo Persada.

Chandra, G., Tjiptino, F. \& Chandra, Y. (2004). Pemasaran Global: Internasionalisasi dan Internetisasi. Ed. I. Yogyakarta: Andi

Desruelle, P. \& Burgelman, C. J. (2001). The Impact of E-commerce on The Value Chain, The Journal of Policy, Regulation and Strategy for Telecomunication, Information and Media, 3 (6): 485-497.
Gaertner, N. dan Smith, M., (2001). E-commerce in a Web-based Environment: Auditing Relative Advantages in The Australian Health Sector, Managerial Auditing Journal, 16 (6): 347-365.

Ian, M. K., Philip, G., (2003). Bussines Transformation, Information teknology And competitive Strategies, learning to fly International journal of information Management.

Jinling, Chang et all, (2009). Modelling Ecommerce Website Quality with Quality function Deployment, IEEE International Comperence on Deployment e - bussiness Engineering.

Kottler, P. (2002). Manajemen Pemasaran. Edisi Milenium. Jakarta: Prehallindo.

Naim, Ngainun. 2011. Dasar-dasar Komunikasi Pendidikan. Jogjakarta: Ar-ruzz Media.

Suryadi, Ace. (2002), Pendidikan, Investasi Sumberdaya Manusia dan Pembangunan. Jakarta: Balai Pustaka

Syamsudin. (2007). E- Commerce dan Pemasaran Produk usaha kecil dan menengah, journal Manajemen dan Bisnis, Surakarta. 